\title{
Sakarya Havzası Su Kalitesi Parametrelerinin Yapay Sinir Ağları ile Modellenmesi
}

\author{
Hatice Çıtakoğlu ${ }^{*}$, Yusuf Özeren ${ }^{2}$ \\ ${ }^{1 *}$ Erciyes Üniversitesi, Mühendislik Fakültesi, İnşaat Mühendisliği Bölümü, Kayseri, Türkiye (ORCID: 0000-0001-7319-6006), hcitakoglu@erciyes.edu.tr \\ ${ }^{2}$ Devlet Su İșleri Genel Müdürlüğ̈̈, 12. Bölge Müdürlügü̈, Kayseri, Türkiye (ORCID: 0000-0003-1233-3403), yusufozeren@dsi.gov.tr
}

(2nd International Conference on Access to Recent Advances in Engineering and Digitalization (ARACONF)-10-12 March 2021)

(DOI: 10.31590/ejosat.898046)

ATIF/REFERENCE: Çıtakoğlu, H. \& Özeren, Y. (2021). Sakarya Havzası Su Kalitesi Parametrelerinin Yapay Sinir Ağları ile Modellenmesi. Avrupa Bilim ve Teknoloji Dergisi, (24), 10-17.

$\ddot{O} z$

Su canlı yaşamı için en önemli doğal kaynaklardan birisi olup hızlı nüfus artışı, tarım ve sanayide suyun bilinçsiz kullanımı ile kirletilmesi telafisi zor durumlara neden olabilecektir. Su kalitesi sadece insan yaşamı için değil, diğer tüm canlı yaşamı için de önemlidir. Su kirliliği ile ilgili en önemli parametrelerden birisi çözünmüş oksijendir. Çözünmüş oksijen suda canlı yaşamı için hayatidir. Yapay sinir ağlarının su yönetimindeki diğer uygulamalarla birlikte su kalitesi parametreleri için de kullanım alanı vardır. Su kalitesi parametrelerinin yapay sinir ağları ile modellenmesiyle önemli kazanımlar sağlanabilir. Bu çalışmada, Sakarya Havzası gözlem istasyonlarına ait 1995-2014 yılları arasındaki aylarda ölçülmüşs su kalitesi verileri ile çözünmüş oksijen değerinin modellemesi yapılmıştır. Modellede giriş verileri; sıcaklık, elektriksel iletkenlik, $\mathrm{pH}$, biyolojik oksijen ihtiyacı ve aylar çıkış verisi ise çözünmüş oksijendir. Toplamda 1388 adet veri mevcuttur. Toplam verinin \%80'ni (1107 veri) eğitmede, \%20’si (281 veri) test verisi olarak kullanılmıştır. Bu çalışmamızda modellerin tahmin başarısııı ölçmek için, Kök Ortalama Karesel Hata, Ortalama Mutlak Hata, Ortalama Mutlak Bağıll Hata ve Nash-Sutcliffe Model Verimlilik Katsayısı ölçütleri kullanılmıştır. Çalışma sonucunda hata kriterleri makul değerlerde olup tahmin etme gücü yüksektir.

\section{Sakarya Basin Water Quality Parameters Modeling With Artificial Neural Networks}

\begin{abstract}
Water is one of the most important natural resources for living life, and its rapid population growth, unconscious use of water in agriculture and industry and its pollution may lead to difficult situations. Water quality is important not only for human life but also for all other living things. One of the most important parameters regarding water pollution is dissolved oxygen. Dissolved ox ygen is vital to aquatic life. Artificial neural networks have uses for water quality parameters along with other applications in water management. Significant gains can be achieved by modeling water quality parameters with artificial neural networks. In this study, the modeling of the dissolved oxygen value with the water quality data measured in the months between 1995-2014 belonging to the Sakarya Basin monitoring stations was made. Temperature, electrical conductivity, $\mathrm{pH}$, biological oxygen demand, and months are used as input data in model. Also, dissolved oxygen ise used output data. There are 1388 data in total. $80 \%$ of the total data (1107 data) was used for training, 20\% (281 data) was used as test data. In this study, Root Mean Square Error, Mean Absolute Error, Mean Absolute Relative Error, and Nash-Sutcliffe Model Efficiency Coefficient criteria were used to measure the prediction success of the models. As a result of the study, the error criteria are reasonable and its predictive power is high.
\end{abstract}

Keywords: Sakarya basin, Water quality, Artificial neural networks, Dissolved oxygen.

\footnotetext{
*Sorumlu Yazar: hcitakoglu@erciyes.edu.tr
} 


\section{Giriş}

$\mathrm{Su}$, hayatın her alanında en çok ihtiyaç duyulan temel bir gereksinimdir. Dünyanın dörtte üçünün sularla kaplı olması çok fazla miktarda suya sahip olduğumuzu düşündürse de insanların kullanımına yönelik olan tatlı su miktarı ne yazık ki çok sınırlıdır. Okyanus ve denizlerde, yeryüzündeki suların büyük bir miktarı bulunsa da içme suyu ya da sulama suyu olarak kullanılamayacak nitelikte tuzlu sulardır. Yaşam için tatlı su ihtiyac1, yüzeysel sular ve yeraltı su kaynaklarından sağlanmaktadır. Hayatın devamı için bu denli büyük bir öneme sahip olan sular, insan faaliyetleri ile maalesef kirletilmektedir. Günümüzde ve gelecekte su kirliliği önemli sorunlardan birisi olacaktır. Su kirliliğine birçok unsur etki etmektedir (Schwarzenbach, Egli, Hofstetter, Gunten, ve Wehrli, 2010). Bunlara; nüfus yoğunluğunun fazla olduğu yerleşim yerlerindeki evsel atıklar, sanayi kuruluşlarının yoğunlaştığı bölgelerdeki sanayi atıkları ve tarım yapılan alanlardaki kimyasal gübreler ve tarım ilaçları örnek olarak verilebilir (Tunç Dede ve Sezer, 2017). Dünya üzerinde sınırlı miktarda bulunan su kaynaklarının hızlı nüfus artışı, tarım ve sanayide suyun bilinçsiz kullanımı ile kirletilmesi telafisi zor durumlara neden olabilecektir. Bilim insanları gelecekteki su kaynaklarının kirlenmesini önlemek, su kalitesinin korunmasını sağlamak ve etkilerini kontrol altına almak için birçok çalışma yapmıştır ve çalışmalar devam etmektedir (Zheng, Chen ve Zhang, 2004).

Dünya'da tatlı su kaynaklarının kısıtlı olması yanında ülkemiz dünyada su kaynaklarının kıt olduğu bir coğrafyada yer almaktadır. Ülkemizde su yönetim sürecinin daha dikkatli ve doğru politikalar geliştirilerek sürdürülmesi çok daha fazla önem kazanmıştır. Nüfus artışı ile beraber tüm sektörlerde artması muhtemel su talebi ve küresel iklim değişikliğinin iyi yönetilmesi gerekmektedir (Aküzüm, Çakmak ve Gökalp, 2010). $\mathrm{Su}$ yönetim sürecinde, su kalitesi önemli bir yere sahip olacaktır ve suyun kalitesinin korunması ile sürdürülebilirliğinin sağlanması çok önemlidir.

$\mathrm{Su}$ kalitesinin sadece insan yaşamı için değil, diğer tüm canlı yaşamı için de önemini kavramamız gerekir. Su kalitesi ilk aşamada suyun atmosferde oluşumu ve yeryüzüne yağmur ve kar şeklinde düşmesiyle olur. Hidrolojik çevrim ile beraber su dolaşımı esnasında çevresel etkiler neticesinde su kirliliği oluşacaktır ve bu kirlilik bir yerden bir başka bölgeye taşınabilecektir. Sulardaki doğal kirlenme yanında insanlar tarafından özellikle endüstriyel faaliyetler ile birlikte kimyasal, fiziksel, biyolojik ve radyoaktif kirlilikler meydana gelir (MEGEP Yayınları, 2011). Su kalitesi parametrelerinin her biri ayrı bir öneme sahiptir ve belirli periyotlarla değişiminin izlenmesi gerekmektedir. Renksiz ve kokusuz bir madde olan suların; bulanıklığı, sıcaklığı, rengi ve kokusu fiziksel parametrelerindendir. Suyun sıcaklığı, suda canlı yaşamını etkileyebilecektir. Sıcaklık arttıkça suda reaksiyon hızı artacak, sudaki çözünmüş oksijen miktarı azalacaktır (MEGEP Yayınları, 2011). Suyun asidik ve bazik özelliği pH ile ifade edilir. Endüstriyel kirlenmenin etkisi $\mathrm{pH}$ değerinde görülebilir. Suda insan sağlığına zararlı ağır metaller diye tanımladığımız cıva, kurşun, arsenik v.d. bulunmamalıdır. Bütün sular elektrik içerir. Elektriksel iletkenlik suyun elektrik akımını iletme kapasitesini ifade eder (Güler, 1997). İletkenlik değerindeki artış su kirliliğine işarettir. $\mathrm{Su}$ kirlenmesi ile ilgili en önemli parametrelerden birisi çözünmüş oksijen (ÇO)'dir. ÇO, sudaki canlı yaşam için hayati bir öneme sahiptir. Oksijenin sudaki çözünürlülüğü, suyun sicaklığı ve sudaki minerallerin derişimlerine bağlıdır. Sudaki aerobik canlı yaşamı için çözünmüş oksijene gereksinim vardır. Su içerisinde oksijenin miktarının azalması ile beraber anaerobik çürüme meydana gelir. Suyun kokusunda değişimler ortaya çıkacaktır. Belirli periyotlarla ölçülen su kalitesi parametrelerinin izlenmesi ile oluşması muhtemel problemlerin önceden engellenmesi sağlanabilir.

Yaşadığımız çevre sürekli bir değişim halindedir. Bu değişimin günümüzde ve gelecekte, çevrede nasıl etkileri olacağını tahmin edebilmek önemli kazanımlar sağlayacaktır. Birçok doğa biliminde kullanım alanı olan yapay zekâ tekniklerinin su yönetimindeki diğer uygulamalarla birlikte su kalitesi parametreleri için de kullanım alanı vardır. Su kalitesi ile ilgili çalışmalarda geçmiş yıllardan elde edilen veriler ile tahminde bulunmak, problemlerin çözümlerinde önemli kolaylıklar sağlamaktadır (Yılmaz, 2015).

Yapay sinir ağlarından; sınıflandırma yapma, teşhis, verileri ilişkilendirme ve yorumlama gibi pek çok alanda yararlanılmaktadır. Özellikle tahmin çalışmalarında çok iyi sonuçlara ulaşılabilmektedir. Yapay sinir ağları (YSA) ile insan beyin yapısının çalışması taklit edilmeye çalışılır. İnsan beyni, tecrübeleri ile sağladığı kazanımlar ile sorunları çözme becerisi gösterir. YSA, insan beynine benzer öğrenmeyi gerçekleştiren bilgisayar sistemleridir. Öğrenme işlemi de örnekler ile gerçekleştirilir. Girdi ve çıktıların sisteme tanıtılması ile ögrenme sağlanır ve daha sonra eğitme işlemi gerçekleştirilir. (Öztemel, 2012). YSA'lar sahip olduğu öğrenme yeteneği ve öğrenme işleminden sonra daha az bilgiye gereksinim duyması, karmaşık matematiksel modelleri daha hızlı çözebilmeleri gibi sahip oldukları özellikleri nedeniyle önemli kazanımlar sağlarlar (Citakoglu, 2017).

Adamowski ve Karapataki (2012), Kıbrıs’ta Lefkoşa kentinin son dönemlerde yaşadığ 1 su krizi sorunu ile ilgili olarak sürdürülebilir su yönetimi için çoklu doğrusal regresyon analizi ve yapay sinir ağlarını kullanarak farklı modeller ile su talebinin tahmini üzerine çalışma yapmışlardır. Yapılan çalışma neticesinde; radyal tabanlı fonksiyon (RBF), gradient-descent (GD) ve Levenberg-Marquardt (LM) olmak üzere üç farklı öğrenme algoritması yapay sinir ağlarında kullanılmış ve performansları karşılaştırılmıştır. LM YSA modelinin diğer iki YSA modeline ve çoklu doğrusal regresyona göre haftalık en yüksek su talebini daha doğru tahmin ettiğini belirtmişlerdir.

Hindistan'ın Gomti Nehri'nde yapmış oldukları çalışmada Singh, Basant, Malik ve Jain (2009), 10 yıllık bir süre ile sekiz gözlem istasyonundan ölçülmüş aylık su kalitesi verileri ile çözünmüş oksijen ile biyolojik oksijen ihtiyacını yapay sinir ağları ile modellemiştir. Modellemede giriş verisi olarak $\mathrm{pH}$, T-Alk, Sertlik, Katı madde, kimyasal oksijen ihtiyacı, NH4-N, NO3-N, Cl, PO4, K, Na olmak üzere 11 değişken su kalitesi verisi kullanılmıştır. Verilerin, 576 (\% 60) âdeti deneme, $192(\%$ 20) âdeti eğitme ve 192 (\% 20) âdeti test verisi olarak kullanılmıştır. Model performans kriterleri olarak Kök Ortalama Kare Hata KOKH ile Determinasyon katsayısı (R2) değerleri kullanılmıştır. Determinasyon katsayısı değerleri, ÇO için 0.76 ile biyolojik oksijen ihtiyacı için 0.77 olarak hesaplanmıştır. Yapay sinir ağlarının nehir su kalitesi modellemeleri için geleneksel modelleme tekniklerine karşı önemli bir alternatif olduğu ortaya konulmuştur.

Nehirlerin su kalitesinin belirlenmesinde çözünmüş oksijen önemli bir yere sahiptir. Sengorur, Dogan, Koklu ve Samandar 
(2005), su kalitesi kontrolü için sınırlı sayıda veri ile yapay sinir ağları kullanarak çözünmüş oksijen değerinin tahmini için çalışma yapmışlardır. Modelleme giriş verisi NO2-N, NO3-N, BOİ, debi ve sicaklık olup model performans kriterleri olarak Ortalama Karesel Hata ile R2 değerleri kullanılmıştır. R2 değeri 0.9186 olan 3 nöron ve tek gizli tabakaya sahip ileri beslemeli YSA ile en iyi tahmin sağlandığı belirtilmiştir. Nehir kirlilik sorunlarının önceden tahmin edilmesinde yapay sinir ağlarından yararlanılabileceği ortaya konulmuştur.

$\mathrm{Bu}$ çalışmanın amac1; Sakarya Havzası gözlem istasyonlarına ait 1995-2014 yılları arasındaki aylarda (Şubat, Nisan, Haziran, Ağustos ve Kasım) ölçülmüş su kalitesi verileri kullanılarak çok katmanlı yapay sinir ağı modeli ile sıcaklık (T), elektriksel iletkenlik (EI), pH, biyolojik oksijen ihtiyacı (BOİ) ve aylar kullanılarak ÇO değerinin modellemesi yapılmıştır. 1995-2014 (20 y1l) y1lları arasındaki 1388 verinin \%80'ni (1107 adet) eğitmede, \%20'si (281 adet) test verisi olarak kullanılmıştır. $\mathrm{Bu}$ çalışmamızda modellerin tahmin başarısını ölçmek için, Karekök Ortalama Karesel Hata, Ortalama Mutlak Hata, Ortalama Karesel Hata, Ortalama Mutlak Bağıl Hata ve Nash-Sutcliffe Model Verimlilik Katsayısı ölçütleri kullanılmıştır. Yapılacak modelleme çalışmasıyla genellikle doğrusal olmayan bu parametrelerin modellemedeki etkisinin ve yapay sinir ağlarına ait üyelik fonksiyonlarının doğru bir şekilde belirlenmesi amaçlanmıştır.

\section{Materyal ve Metot}

Sakarya Havzası'nda yer alan gözlem istasyonlarına ait 1995-2014 yılları arasındaki Şubat, Nisan, Haziran, Ağustos ve Kasım aylarında ölçülmüş su kalitesi verileri ile ÇO değerinin çok katmanlı YSA ile modellemesi yapılmıştır. Modellemede kullanılan bağımsız değişkenler; T, Eİ, pH, BOİ, aylar ve ÇO değerleridir.

\subsection{Sakarya Havzası}

Çalışmamızda ele alacağımız bölge, Türkiye'nin 25 nehir havzasından biri olan Sakarya Havzasıdır. Sakarya Havzası ülkemizin kuzeybatısında yer almakta olup Susurluk, Konya, Akarçay, Batı Karadeniz ve Kızılırmak Havzaları ile komşudur. Havza kendi içerisinde 6 alt havzaya bölünmüştür. Alt havzalar nehrin doğduğu noktadan Karadeniz'e döküldüğü noktaya kadar; Yukarı Sakarya, Porsuk Çayı, Ankara Çayı, Orta Sakarya, Göksu-Karasu ve Aşağı Sakarya Alt Havzası şeklindedir Sakarya Havzasının ana kolu Sakarya Nehridir. Sakarya Nehri, Kızılırmak ve Fırat nehirlerinden sonra Türkiye'nin üçüncü en uzun, Kuzeybatı Anadolu'nun ise en büyük akarsuyudur. Eskişehir'in güneyinde yer alan Çifteler Sakaryabaşı kaynaklarından doğar ve Sakarya'nın Karasu ilçesinden Karadeniz'e dökülür. Nehrin drenaj alanı 58.160 km2 olup başlangıcında yer alan bazı kaynaklarının kuruduğu göz önüne alınırsa kolları ile birlikte toplam uzunluğu 720 km'dir (Sakarya Havzas1, Proje Nihai Raporu, 2013).

Sakarya Havzasında, ülkemizin başkenti ve önemli bir sanayi şehri olan Ankara ile Sakarya ve Eskişehir gibi gelişmiş büyük şehirler bulunmaktadır. Havzada yaşayan toplam nüfusun ülke nüfusuna oranı yaklaşık olarak \%10'lar civarındadır. Havzada endüstriyel kuruluşların bulunması yanında drenaj alanında yer alan arazinin önemli bir kısmında tarım ve hayvancılık faaliyetleri sürdürülmektedir. Ülkemizin önemli ovaları; Polatlı, Pamukova ve Adapazarı Ovaları havzada yer almaktadır. İlgili kuruluşlarca yapılmış sulama tesisleri ile sulama alanları önemli büyüklüğe sahiptir.

Sakarya Havzasında, konumu ve kapladığı geniş alan nedeniyle çeşitli iklimler görülmektedir. Kuzey kesimlerde 1lıman ve yağışlı Karadeniz iklimi görülürken diğer kesimlerde tipik İç Anadolu ikliminin etkisi vardır (Sakarya Havzası, Proje Nihai Raporu, 2013). İklim farklılıkları ile beraber yağış miktarları da kuzey ve güney kesimlerde farklılık gösterir. Kuzeyde Karadeniz yağış rejimi hakimken, güneyde ise İç Anadolu yağış rejimi görülmektedir.

Sakarya Havzası'nda önemli göller ve çok sayıda baraj gölü bulunmaktadır. Havza'nın önemli bir su kaynağı olan Sapanca Gölü, Sakarya ilinin içme ve kullanma suyu ihtiyacını karşılamaktadır. Gölün su toplama havzasının büyüklüğü yaklaşık 252 km2'dir. Ayrıca, Ankara'da yer alan Mogan ve Eymir Gölleri de havzada bulunmaktadır. Ülkemizin önemli Hidroelektrik Santral (HES) tesisi olan Sarıyar Hasan Polatkan Barajı havza sınırları içerisinde yer alır (Yaykıran, 2016). 1936 yılında işletmeye açılmış ve Su İşleri tarihinde Cumhuriyetin ilk barajı olan Çubuk I Barajı'da havza sınırlarında bulunur (DSİ, 2021). Ankara ilinin içme ve kullanma suyunu sağlayan Çubuk I, Çubuk II, Bayındır, Kurtboğazı, Çamlıdere, Eğrekkaya, Akyar, Kavşakkaya Barajları ile Eskişehir ilinin içme ve kullanma suyunu sağlayan Porsuk Çayı üzerine inşaa edilmiş Porsuk Barajı havzada yer alan önemli barajlardandır.

Sakarya Havzası, ülkemizin en büyük iki şehri Ankara ve İstanbul arasında yer alması sebebiyle sanayi, ticaret, ulaşım ve turizm gibi pek çok ekonomik ve kültürel faaliyet açısından Türkiye'nin diğer yerlerine göre daha gelişmiş durumdadır. Havzada nüfus yoğunluğuna göre su miktarı kısıtlıdır. Sürdürülebilir su yönetimi için suyun kalitesinin korunması gerekmektedir.

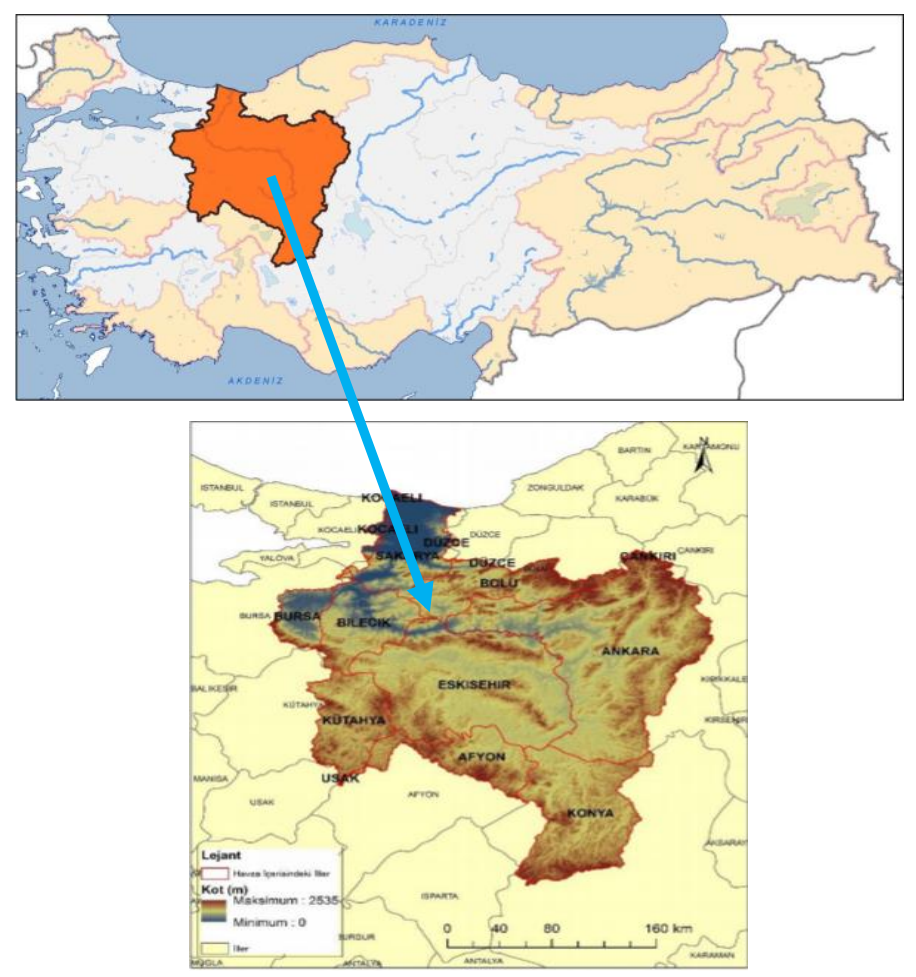

Şekil 1. Sakarya Havzasının ülkemizdeki konumu (Sakarya Havzası, Proje Nihai Raporu, 2013; Yaykıran, 2016) 


\subsection{Yapay Sinir Ăgları (YSA)}

Son yıllarda bilgisayar yazılımları, dijital dünyamızın vazgeçilmezleri olmuştur. Yapay zekâ teknolojilerinden hayatımızın her alanında faydalanmaktayız. Yapay Sinir Ağları, insan beyninin öğrenmesi model alınarak yeni bir bilgi üretme yöntemidir. YSA; insan beynini taklit edip öğrenme işlemini sağlayarak yeni bilgiler üretebilmesi ve geleceğe dönük tahminde bulunabilmesi amacıyla geliştirilen bilgisayar sistemleridir. Yapay sinir ağları modellemesi, çok zor çalışmalarda ciddi kolaylıklar sağlamaktadır (Öztemel, 2012). YSA modelleri, örnekleri kullanarak öğrenirler ve farklı öğrenme algoritmaları ile öğrenebilirler.

Yapay sinir ağlarından insan beyin sisteminin çalışması örnek alınarak çalışması istenir. Bundan dolayı biyolojik sinir sistemi ile yapay sinir ağları arasında benzerlikler vardır. YSA'nın çalı̧̧masındaki temel birim yapay sinir hücreleridir. Yapay sinir hücreleri; girdiler, ağırlıklar, toplama (birleştirme) fonksiyonu, aktivasyon (transfer) fonksiyonu ve çıkış olmak üzere beş bileşene sahiptir. Girdiler, dış ortamdan alınan bilgileri yapay sinir ağına getirirler. Ağırlıklar, öğrenilmiş bilgilerin saklandığ 1 ve depolandığ yerdir. Matematiksel nöronların önemli unsurlarındadır. Toplama (birleştirme) fonksiyonu, girdiler ile ağırlıklarının çarpımlarının toplamını transfer fonksiyonuna aktaran işlem elemanıdır. Aktivasyon (transfer) fonksiyonu, ağırlıklı girdi değerlerinin aktivasyonundan ve çıkış değerinin tanımlanmasını gerçekleştirir. Çıkış, transfer işlevinin sonucudur.

Yapay sinir hücreleri bir araya gelerek yapay sinir ağlarını oluştururlar. YSA'dan çok karmaşık olayları çözümlerken faydalanılır. YSA karmaşık ilişkileri öğrenebilir ve daha önce karşılaşmadığı problemlere çözümler getirebilir. Eksik ve kısmen hatalı verileri ise verilere bağlı kalmadan değerlendirebilir (Yavuz ve Deveci, 2012). YSA ile modelleme çalışmalarında, verilerimiz girdi olarak işlenecek daha sonra YSA'ların öğrenme özelliğinden yararlanarak ve tüm ihtimaller değerlendirilerek en iyi diye nitelendirebileceğimiz çıkış verisi elde edilecektir. YSA, öğrenme ile kazanacağ problemlerin çözümünü gerçekleştirebilecektir.

Sadece girdi ve çıktı katmanından oluşan yapay sinir ağı tek katmanlı ağdır. $\mathrm{Bu}$ ağlar karmaşık işlemlerin hesaplamalarında zayıf kalabilirler. Girdi ve çıktı katmanı yanında birden fazla gizli katmanda içeren ağ yapıları çok katmanlı ağ yapılarıdır. Bu ağlar yapıları eğitim ve test aşamaları ile çalıştırılır. Eğitim aşaması ile öğrenme algoritması için ağırlıklar hesaplanır ve bu değerler için çıktı hesaplanır (Yavuz ve Deveci, 2012). Test aşaması ile sistem test edilir.

\subsection{1. Çok Katmanlı Yapay Sinir A ğları (ÇKYSA)}

Doğrusal olaylarla ilgili çalışmalarda YSA'ların ilk modelleri çözümler getirebilirken doğrusal olmayan olaylar için çok katmanlı yapay sinir ağları (ÇKYSA) geliştirilmiştir. ÇKYSA'da girdi ve çıktı katmanının kaç elemana sahip olacağı probleme göre belirlenir. Yine ara katman için belirlenmiş eleman sayıs yoktur. Deneme yanılma ile eleman sayıs1 belirlenmelidir. ÇKYSA'da bilgi akışı girdi katmanı, ara katman ve çıktı katmanı şeklinde ileri doğrudur. ÇKYSA'nın eğitim performansını ölçmek amacıyla eğitim aşamasından sonra, eğitim aşamasında ağın görmediği örnekler gösterilerek bunlara ağ nasıl karar verdiği incelenir. Görmediği bu örneklere doğru cevap vermesi model performansının iyi olduğunu gösterir (Öztemel, 2012).

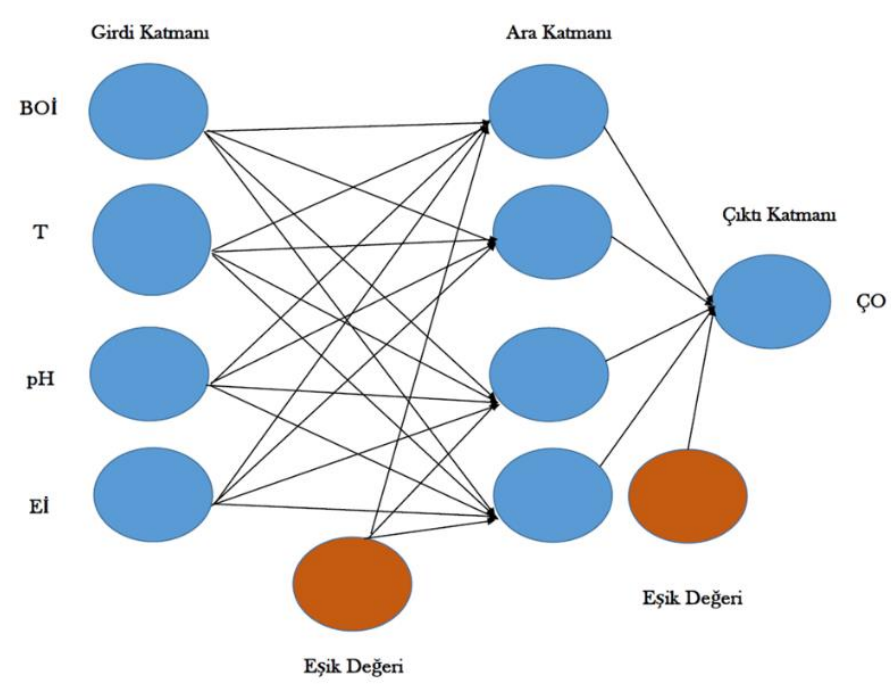

Şekil 2. Çok Katmanlı Yapay Sinir Ağının (ÇKYSA) Yapısı

\subsection{Model Performansının Belirlenmesi}

YSA modelleri ile elde edilen sonuçlar; Ortalama Mutlak Hata (OMH), Ortalama Mutlak Bağıl Hata (OMBH) ve NashSutcliffe Model Verimlilik Katsayısı (NSE) kriterlerine göre karşılaştırılmıştır. Bunlardan; KOKH, OMH, OKH ve OMBH değerleri 0'a yaklaştıkça daha doğru ve güvenilir tahminlerin yapıldığ anlaşılmaktadır. NSE değeri ise eksi sonsuz ve 1 arasında değişmektedir. $\mathrm{Bu}$ parametre değerinin 1 olması istenmektedir ve bu durum yüzde yüz başarıyı temsil etmektedir. Literatürde NSE değerinin $0.3-0.5$ arasında olması düşük tahmin başarısı gerçekleştiğini, $0.5-0.7$ arası kabul edilebilir başarıyı, 0.7-0.9 arası yüksek tahmin başarısını, $0.9-1$ arası ise mükemmel tahmin başarısını temsil etmektedir. Değerlere ait denklemler aşağıda ifade edilmiştir.

$$
\begin{aligned}
& \mathrm{OMH}=\frac{1}{\mathrm{n}} \sum_{\mathrm{i}=1}^{\mathrm{n}}\left|\mathrm{CO}_{\mathrm{T}, \mathrm{i}}-\mathrm{CO}_{\ddot{O}, \mathrm{i}}\right| \\
& \text { OMBH }=\frac{1}{n} \sum_{\mathrm{i}=1}^{\mathrm{n}}\left|\frac{\mathrm{CO}_{\mathrm{T}, \mathrm{i}}-\mathrm{ÇO}_{\ddot{O}, \mathrm{i}}}{\mathrm{COO}_{\ddot{0}, \mathrm{i}}}\right| \\
& \mathrm{OKH}=\frac{1}{\mathrm{n}} \sum_{\mathrm{i}=1}^{\mathrm{n}}\left(\mathrm{CCO}_{\mathrm{T}, \mathrm{i}}-\mathrm{CCO}_{\ddot{O}, \mathrm{i}}\right)^{2} \\
& \mathrm{NSE}=1-\frac{\sum_{\mathrm{i}=1}^{\mathrm{n}}\left(\mathrm{COO}_{\ddot{0}, \mathrm{i}}-\mathrm{ÇO}_{\mathrm{T}, \mathrm{i}}\right)^{2}}{\sum_{\mathrm{i}=1}^{\mathrm{n}}\left(\mathrm{COO}_{\ddot{0}, \mathrm{i}}-\overline{\mathrm{CO}_{0}}\right)^{2}}
\end{aligned}
$$

Burada ÇOT, YSA modelleri ile tahmin edilen çözünmüş oksijen; ÇOÖ, Devlet Su İşleri (DSİ) tarafindan ölçülen çözünmüş oksijen; $\overline{C ̧ O_{\ddot{O}}}$, DSİ tarafından ölçülen çözünmüş oksijen değerlerinin ortalamasını; $n$, serinin uzunluğunu ifade etmektedir. 


\section{Araştırma Sonuçları ve Tartışma}

Türkiye'nin 25 nehir havzasından biri olan Sakarya Havzası'nda yer alan gözlem istasyonlarına ait 1995 - 2014 yılları arasındaki Şubat, Nisan, Haziran, Ağustos ve Kasım aylarında ölçülmüşs su kalitesi verileri ile ÇO değerinin ÇKYSA ile modellemesi yapılmıştır. Giriş verileri olan; T, Eİ, pH, BOİ, aylar ve ÇO değerleri MATLAB programı yardımıyla giriş verisi olarak işlenerek ÇO değeri tahmin edilmeye çalışılmıştır. 1995 2014 (20 y1l) y1lları arasındaki 1388 verinin \%80'ni (1107 adet) eğitmede, \%20'si (281 adet) test verisi olarak kullanılmıştır.

Tablo 1'de eğitme ve test değişkenlerine ait verilerin temel istatistik özellikleri verilmiştir. ÇO ve pH değişkenlerinin Csx katsayıları sıfırdan küçük olduğu için sola çarpık oldukları belirlenmiş olup diğer değişkenlerin Csx katsayıları sıfırdan büyük oldukları için sağa çarpık dağılıma sahip oldukları görülmüştür. BOİ, Eİ ve pH değişkenleri $\mathrm{Ck}$ katsayısının sıfırdan büyük olması sebebiyle olasılık yoğunluk dağılımında sivri özellik göstermektedir. Diğer değişkenler ise Ck katsayısının sıfırdan küçük olması sebebiyle basık dağılım özelliği göstermektedir. Csx ve Ck katsayıları sıfırdan farklı olmasıyla birlikte bu çalışmada kullanılan giriş-çıkış verileri normal dağılım özelliği göstermemektedir. Cv katsayısına göre olasılık yoğunluk fonksiyonu en değişken olan veri, en küçük ortalamaya sahip olan ÇO'dur. Aynı zamanda Cv katsayısının en küçük değere sahip olması nedeniyle $\mathrm{pH}$ diğer verilerden en az değişken özelliğe sahiptir.

Tablo 1. Giriş ve çıkış değişkenlerinin istatistiksel parametreleri (Eğitme ve test değişkenleri)

\begin{tabular}{|c|c|c|c|c|c|c|c|c|}
\hline & & $\mathbf{X}_{\text {ort }}$ & SS & $\mathbf{C}_{\mathbf{v}}$ & Min & Mak & $\mathrm{C}_{\mathrm{sx}}$ & $\mathbf{C}_{\mathrm{k}}$ \\
\hline \multirow{5}{*}{ 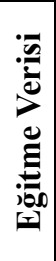 } & $\mathrm{T}\left({ }^{\circ} \mathrm{C}\right)$ & 14.524 & 5.698 & 39.23 & 0.00 & 29.5 & 0.11 & -0.75 \\
\hline & $\mathrm{pH}$ & 7.778 & 0.346 & 4.45 & 4.16 & 9.4 & -1.09 & 11.22 \\
\hline & Eİ (mikromhos/cm) & 836.90 & 425.30 & 50.82 & 193 & 6680 & 3.58 & 39.88 \\
\hline & BOİ (mg/L) & 22.37 & 57.12 & 255.32 & 0.27 & 626 & 6.48 & 50.46 \\
\hline & $\mathrm{ÇO}\left(\mathrm{mg} \mathrm{O}_{2} / \mathrm{l}\right)$ & 7.108 & 3.179 & 44.73 & 0.00 & 14 & -0.31 & -0.81 \\
\hline \multirow{5}{*}{ 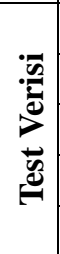 } & $\mathrm{T}\left({ }^{\circ} \mathrm{C}\right)$ & 15.083 & 6.202 & 41.12 & 2 & 30 & 0.08 & -0.85 \\
\hline & $\mathrm{pH}$ & 7.8657 & 0.4745 & 6.03 & 6.2 & 9.3 & -0.01 & 0.74 \\
\hline & Eİ (mikromhos/cm) & 841.8 & 387 & 45.98 & 212 & 2670 & 0.98 & 2.2 \\
\hline & BOİ (mg/L) & 9.899 & 16.264 & 164.3 & 0.6 & 160 & 4.96 & 34.49 \\
\hline & $\mathrm{ÇO}\left(\mathrm{mg} \mathrm{O}_{2} / \mathrm{l}\right)$ & 7.79 & 2.709 & 34.77 & 0.4 & 13.5 & -0.52 & -0.23 \\
\hline
\end{tabular}

Bu çalışmada; ÇO değerinin tahmininde kullandığımız YSA modellerinin tamamı için ÇKYSA modellerinden yararlanılmıştır. Giriş ve çıkış katmanları arasında kullanılan aktivasyon fonksiyonları olarak tanjant sigmoid transfer fonksiyonu (tansig) ile logaritmik sigmoid transfer fonksiyonu (logsig) kullanılmıştır. Öğrenme algoritması olarak da standart sayısal optimizasyon tekniklerinden birisi olan Levenberg Marquardt öğrenme algoritması seçilmiştir. 1 gizli katmanlı modelde nöron sayısı $1-10$ ve iterasyon sayısı $1-100$ aralığında deneme-yanılma yapılarak en düşük hata kriterini veren model tespit edilmiştir.

Tablo 2'de görüleceği üzere ÇKYSA modeli ile farklı kombinasyonlar denenerek çözünmüş oksijen değerini en iyi tahmin edecek yöntemler araştırılmıştır. İlk adımda bağımsız değişkenlerimiz olan BOİ, Aylar, T, Eİ, pH değerleri modelimize 1 girişli olarak tanımlanmıştır. Hata kriteri olan determinasyon katsayısı $\left(\mathrm{R}^{2}\right)$ değerine göre 1 girişli analizler neticesinde en iyi sonuçları BOİ değişkeni vermiştir. Bu modele göre giriş ve çıkış fonksiyonları tanjant sigmoid, gizli düğüm numarası 2 ve devir sayıs 94 olarak bulunmuştur. Daha sonra 2 girişli analizler için BOİ değeri ile diğer değişkenler ayrı ayrı tanımlanarak modelimiz oluşturulmuştur. Hata kriteri olan $\mathrm{R}^{2}$ değerine göre 2 girişli analizler neticesinde en iyi sonuçları BOİ-Aylar değişkenleri vermiştir. $\mathrm{Bu}$ iki girişli modele göre giriş fonksiyonu logaritmik sigmoid ve çıkış fonksiyonu tanjant sigmoid, gizli düğüm numarası 6 ve devir sayısı 70 olarak bulunmuştur. 2 girişli analizlerin R2 değerinin 1 girişli analizlere göre daha iyi olduğu görülmüş olup 1 girişli analizlerin yeterli olmayacağı anlaşılmıştır. Daha sonraki adımda 3 girişli analizler yapılmıştır. Hata kriteri olan R2 değerine göre 3 girişli analizler neticesinde en iyi sonuçları $\mathrm{BO} \dot{\mathrm{I}}-\mathrm{T}-\mathrm{pH}$ değişkenleri vermiştir. $\mathrm{Bu}$ modele göre giriş ve çıkış fonksiyonları logaritmik sigmoid, gizli düğüm numarası 4 ve devir sayısı 19 olarak bulunmuştur. Yapılan 3 girişli analizlerin diğer analizlere göre, $\mathrm{R}^{2}$ değerinin 1 daha çok yaklaştığı görülmüştür. Giriş değerimizi 4'e çıkararak analizler yapılmaya devam edilmiş olup 2 farklı modele ait sonuçlar alınmıştır. 4 değişkenli modellerimiz; BOİ-T-pH-EI ve BOI-Aylar-T-pH'dır. Hata kriteri olan $\mathrm{R}^{2}$ değerine göre 4 girişli analizler neticesinde en iyi sonuçları BOI-T-pH-EI değişkenleri vermiştir. $\mathrm{Bu}$ modele göre giriş fonksiyonu logaritmik sigmoid ve çıkş̧ fonksiyonu tanjant sigmoid, gizli düğüm numarası 4 ve devir sayısı 55 olarak bulunmuştur.

$\mathrm{Bu}$ çalışmada, modellerin doğruluğunu dğerlendirilirken literatür de sik kullanılan performans kriterlerinden yararlanılmıştır. Modellerin değerlendirilmesinde $\mathrm{OMH}, \mathrm{OKH}$, KOKH, OMBH gibi klasik hataların yanı sıra Nash-Sutcliffe Model Verimlilik Katsayısı ölçütleri de kullanılmıştır.

$\mathrm{OMH}, \mathrm{OKH}, \mathrm{KOKH}$ ve $\mathrm{OMBH}$ hatalarının en küçük değerleri daha doğru ve güvenilir tahminlerin yapıldığını göstermektedir. Tablo 3'de de görüleceği üzere bu hata değerlerine ait en küçük değerler 4 girişli $\mathrm{BOI}-\mathrm{T}-\mathrm{pH}-\mathrm{EI}$ modelimizle bulunmuştur.

NSE değeri $-\infty$ ve 1 arasında değişmektedir. NSE değerinin 1 olması istenmektedir ve bu durum yüzde yüz başarıyı temsil etmektedir. Literatürde NSE değerinin $0.3-0.5$ arasında olması düşük tahmin başarısı gerçekleştiğini, 0.5-0.7 arası kabul edilebilir başarıyı, 0.7-0.9 arası yüksek tahmin başarısını, 0.9-1 
arası ise mükemmel tahmin başarısını temsil etmektedir. Tablo 3 'de yer alan NSE değerlerimiz değerlendirildiğinde; BOİ-Aylar ve BOİ-T-Eİ değerlerine ait test ve eğitme sonuçları ile $\mathrm{BOI}-\mathrm{T}-\mathrm{pH}$ değerlerine ait test sonuçlarının $0.5-0.7$ arasında kalarak kabul edilebilir başarıyı temsil ettiği, BOİ-T-pH değerine ait eğitme sonucu ile BOI-T- $\mathrm{pH}-\mathrm{EI}$ değerlerine ait eğitme ve test sonucu $0.7-0.9$ aralığında kaldığından yüksek tahmin başarısını temsil etmektedir.

Tablo 2. ÇO tahmininde farklı girişli veriler için modellere ait değerler ve bu modellere ait determinasyon katsayısı değeri $\left(R^{2}\right)$

\begin{tabular}{|c|c|c|c|c|c|}
\hline Değişkenler & $\begin{array}{c}\text { Gizli } \\
\text { katmandaki } \\
\text { aktivasyon } \\
\text { fonksiyonu }\end{array}$ & $\begin{array}{c}\text { Çıkış } \\
\text { katmandaki } \\
\text { aktivasyon } \\
\text { fonksiyonu }\end{array}$ & $\begin{array}{c}\text { Gizli } \\
\text { katmandaki } \\
\text { nöron sayısı }\end{array}$ & İterayon & $\mathbf{R}^{2}$ \\
\hline BOİ & Tansig & Tansig & 2 & 94 & 0.493 \\
\hline Aylar & Logsig & Logsig & 4 & 35 & 0.224 \\
\hline $\mathrm{T}$ & Logsig & Logsig & 2 & 50 & 0.221 \\
\hline EI & Logsig & Logsig & 2 & 23 & 0.105 \\
\hline $\mathrm{pH}$ & Tansig & Logsig & 4 & 75 & 0.100 \\
\hline BOİ-T & Tansig & Tansig & 3 & 26 & 0.611 \\
\hline BOİ-Aylar & Logsig & Tansig & 6 & 70 & 0.620 \\
\hline BOİ-EI் & Tansig & Logsig & 2 & 28 & 0.536 \\
\hline BOİ-pH & Logsig & Tansig & 4 & 27 & 0.472 \\
\hline BOİ-T-pH & Logsig & Logsig & 4 & 19 & 0.686 \\
\hline BOİ-Aylar-T & Logsig & Tansig & 7 & 78 & 0.648 \\
\hline BOİ-T-Aylar & Logsig & Logsig & 6 & 16 & 0.641 \\
\hline BOİ-T-E & Logsig & Logsig & 4 & 19 & 0.639 \\
\hline BOİ-T-pH-EI & Logsig & Tansig & 4 & 55 & 0.722 \\
\hline
\end{tabular}

Tablo 3. ÇO tahmininde farkl girişli veriler için modellerin ĕgitme ve test verilerine ait hata kriterleri

\begin{tabular}{|l|l|c|c|c|c|c|}
\hline & Veri Grubu & OKH & OMH & OMBH & NSE & $\mathbf{R}^{\mathbf{2}}$ \\
\hline \multirow{2}{*}{ BOİ-Aylar } & Eğitme & 3.30 & 1.40 & 35.32 & 0.672 & 0.672 \\
\cline { 2 - 7 } & Test & 2.87 & 1.30 & 23.41 & 0.613 & 0.620 \\
\hline \multirow{2}{*}{ BOİ-T } & Eğitme & 2.91 & 1.25 & 24.22 & 0.608 & 0.611 \\
\cline { 2 - 7 } & Test & 3.64 & 1.47 & 38.07 & 0.639 & 0.640 \\
\hline \multirow{2}{*}{ BOİ-T-pH } & Eğitme & 2.92 & 1.36 & 35.64 & 0.710 & 0.710 \\
\cline { 2 - 7 } & Test & 2.40 & 1.19 & 22.01 & 0.677 & 0.686 \\
\hline \multirow{2}{*}{ BOİ-T-pH-Eİ } & Ĕgitme & 2.54 & 1.25 & 30.55 & 0.748 & 0.748 \\
\cline { 2 - 7 } & Test & 2.09 & 1.10 & 20.03 & 0.719 & 0.722 \\
\hline
\end{tabular}

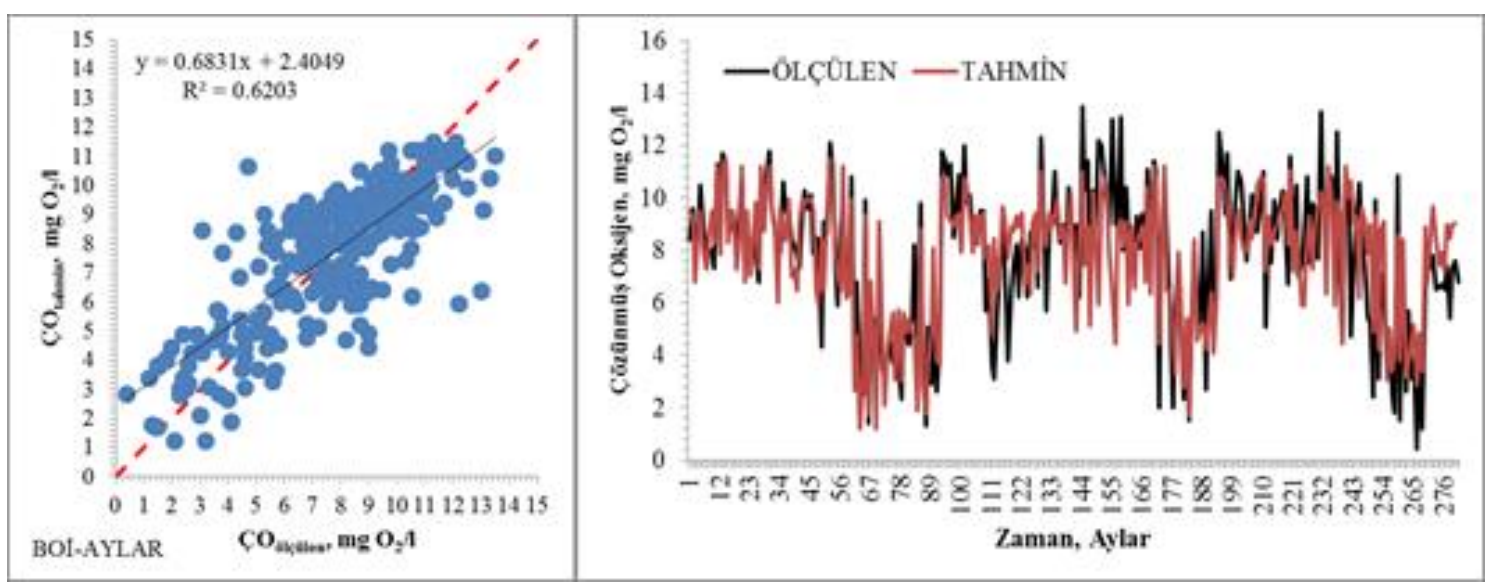

Şekil 3. Tahmin ve ölçülen ÇO değerlerinin BOİ-Aylar değişkenlere ait ÇKYSA test verilerine ait model sonuçları 

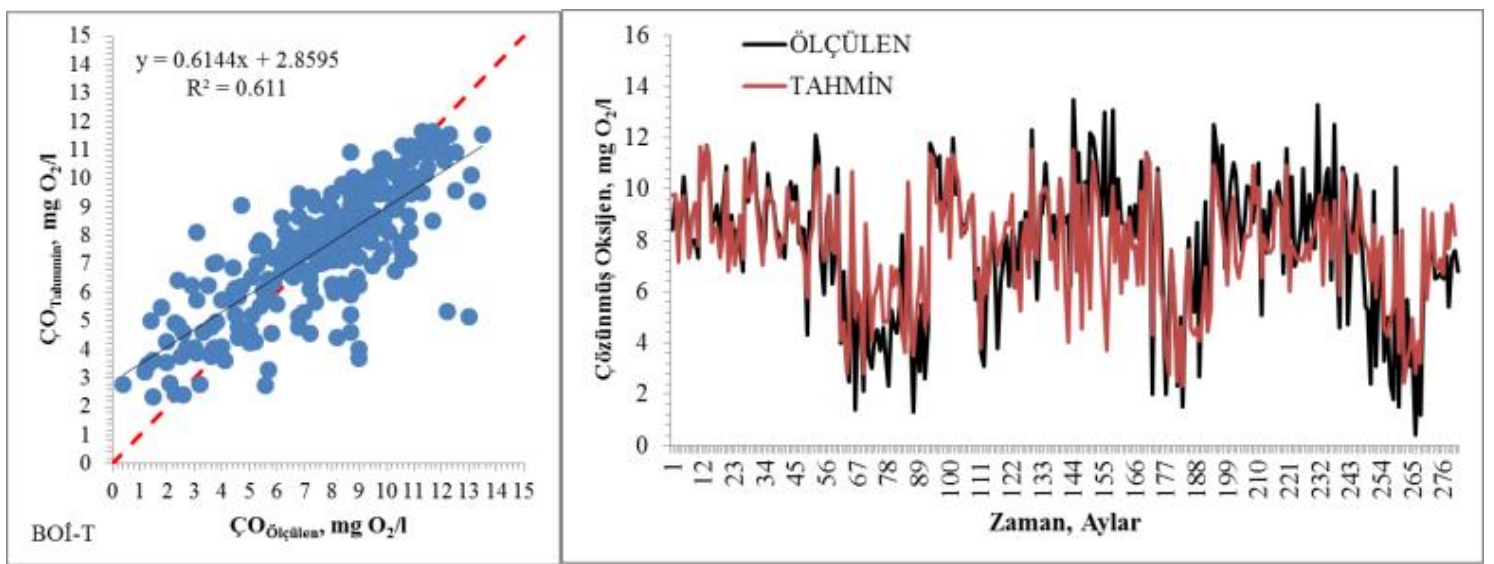

Şekil 4. Tahmin ve ölçülen ÇO değerlerinin BOİ-T değişkenlere ait ÇKYSA test verilerine ait model sonuçları
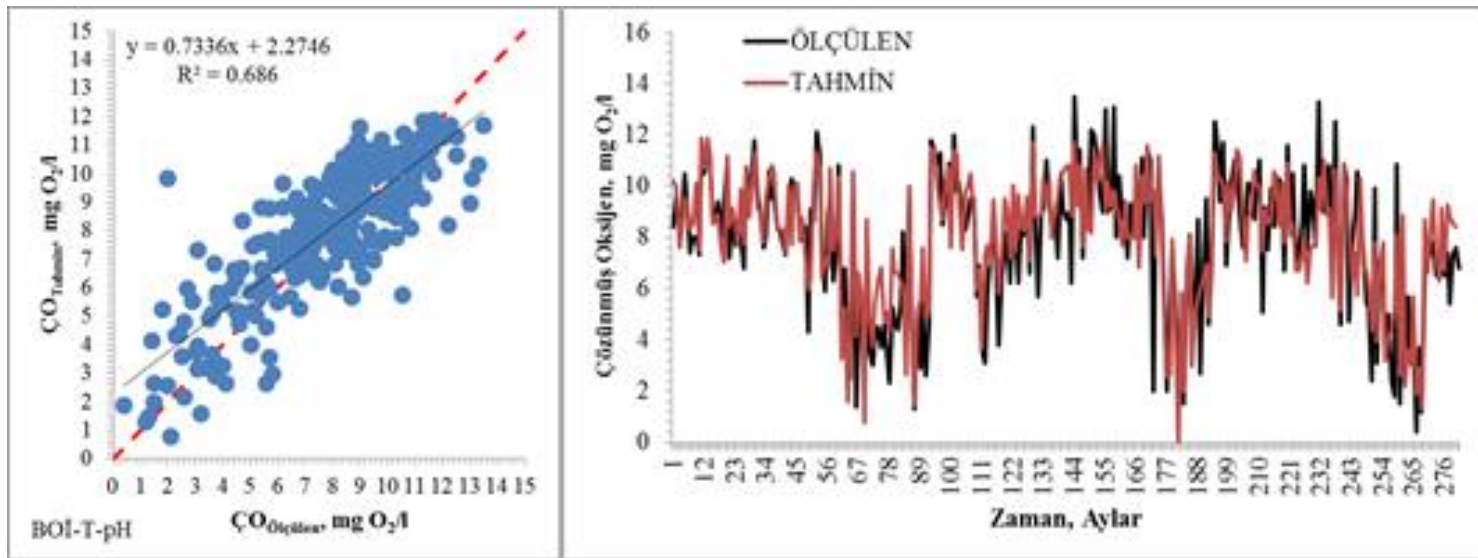

Şekil 5. Tahmin ve ölçülen ÇO değerlerinin BOİ-T-pH değişkenlere ait ÇKYSA test verilerine ait model sonuçları
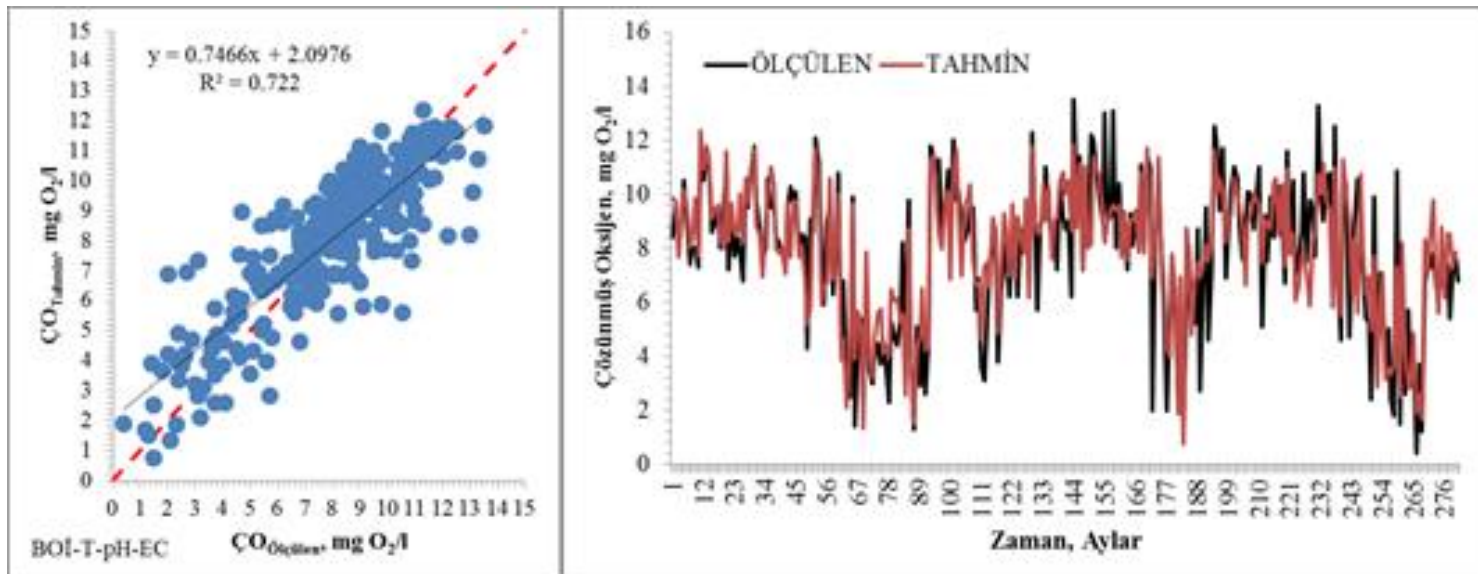

Şekil 6. Tahmin ve ölçülen ÇO değerlerinin BOİ-T-pH-Eİ değişkenlere ait ÇKYSA test verilerine ait model sonuçları

Şekil 3-6'ya göre tahmin ve ölçülen ÇO değerlerinin farklı değişkenlere ait ÇKYSA test verilerine ait model sonuçları yer almaktadır. Şekil 3,4,5'e kıyasla Şekil 6'da tahmin ve ölçülen çözünmüş oksijen değerleri arasındaki ilişkinin doğrusal bir eğriye yaklaştığ 1 görülmektedir. $\mathrm{Bu}$ sonuçlar 4 girişli BOİ-T-pH-Eİ ÇKYSA modelinin diğer modellere göre tahmin değerlerinin daha başarılı olduğunu göstermektedir.

\section{Sonuc}

$\mathrm{Su}$ kaynaklarının kısıtlı olduğu ülkemizde su yönetim sürecinin daha doğru politikalar geliştirilerek sürdürülmesi gerekmektedir. Su kalitesi bu sürecin önemli bir basamağıdır.
Gözlem istasyonlarından alınan su kalitesi verilerinin tahmin çalışmalarında önemli başarıları olan yapay sinir ağları kullanılarak modellemenin yapilmas1 önemli faydalar sağlayacaktır. Bu çalışmada Sakarya havzasına ait 1995-2014 yılları arasındaki su kalitesi parametrelerinden çözünmüş oksijen değeri ÇKYSA ile tahmin edilmiştir. 1'den 4 girişe kadar farklı modeller geliştirilmiş olup modellerin tahmin başarısını ölçmek için KOKH, OMH, OMBH ve NSE ölçütleri kullanılmıştır. BOİ değişkenine bağlı 1 girişli modelde $\mathrm{R}^{2}$ değeri 0.49 ile diğerlerinden daha doğru sonuç vermiştir. Bağımsız değişken sayısının artırılması ile 2 ve 3 girişli modellerde determinasyon katsayısının iyileşmesi sağlanmıştır. ÇKYSA modelleri ile yapılan analizlerde performans kriterlerinin tamamında en iyi 
sonuçların BOİ-T-pH-Eİ modelinden alındığı görülmüştür. Klasik performans değerlendirme kriterlerinden farklı olarak Nash-Sutcliffe Model Verimlilik Katsayısı değeri 0.719 ile 0.7-0.9 aralığında kalarak yüksek tahmin başarısını temsil etmektedir. Bu çalışmada su kalitesi için önemli parametrelerden birisi olan çözünmüş oksijen değerinin diğer su kalitesi parametreleri ile tahmininde ÇKYSA modellerinden yararlanılabileceği ortaya konulmuştur. Farklı kombinasyonlar denenerek model performansları karşılaştırılmıştır.

\section{Kaynakça}

Adamowski, J. F. ve Karapataki, C. (2012). Comparison of multivariate regression and artificial neural networks for peak urban water-demand forecastin: evaluation of different ann learning algorithms. Journal of Hydrologic Engineering, 17 (7), 834-836.

https://doi.org/10.1061/(ASCE)HE.1943-5584.0000472

Aküzüm, T., Çakmak, B. ve Gökalp, Z. (2010). Türkiye'de su kaynakları yönetiminin değerlendirilmesi. Tarım Bilimleri Araştırma Dergisi, 3 (1), 67-74.

http://ijans.org/index.php/ijans/article/view/86

Citakoglu, H. (2017). Comparison of artificial intelligence techniques for prediction of soil temperatures in Turkey. Theoretical and Applied Climatology, 130, 545-556.

https://doi.org/10.1007/s00704-016-1914-7

Devlet Su İşleri (DSI) Genel Müdürlüğü. (2021, 17 Ocak). Erişim adresi https://www.dsi.gov.tr

Güler, Ç. (1997). Su kalitesi. Çevre Sağlı̆̆ı Temel Kaynak Dizisi No:43, Ankara.

Öztemel, E. (2012). Yapay Sinir Ağları. Papatya Yayıncılık, Ankara.

Schwarzenbach, R. P., Egli, T., Hofstetter, T. B., Gunten, U. v. ve Wehrli, B. (2010). Global Water Pollution and Human Health. Annual Review of Environment and Resources, 35, 109-136. https://doi.org/10.1146/annurev-environ-100809-125342

Sengorur, B., Dogan, E., Koklu, R. ve Samandar, A. (2005). Dissolved oxygen estimation using artificial neural network for water quality control. Electronic Letters on Science and
Engineering, 1 (2), 13-16. Erişim adresi https://dergipark.org.tr/en/pub/else/issue/29326/313793

Singh, K. P., Basant, A., Malik, A. ve Jain, G. (2009). Artificial neural network modeling of the river water quality-a case study. Ecological Modelling, 220 (6), 888-895.

https://doi.org/10.1016/j.ecolmodel.2009.01.004

Tunç Dede, Ö. ve Sezer, M. (2017). Aksu çayı su kalitesinin belirlenmesinde Kanada su kalitesi indeks (CWQI) modelinin uygulanması. Gazi Üniversitesi Mühendislik Mimarlık Fakültesi Dergisi, 32 (3), 909-917. https://doi.org/10.17341/gazimmfd.337643

Türkiye Cumhuriyeti Milli Eğitim Bakanlığı, Mesleki Eğitim ve Öğretim Sisteminin Güçlendirilmesi Projesi (MEGEP) Yayınları (2011). Suların Analiz Parametreleri, Çevre Sağlığı, Ankara.

Türkiye Bilimsel ve Teknolojik Araştırma Kurumu Marmara Araştırma Merkezi Çevre ve Temiz Üretim Enstitüsü (2013). Havza Koruma Eylem Planlarının Hazırlanması Projesi Sakarya Havzası, Proje Nihai Raporu, Kocaeli. Erişim adresi:

https://www.tarimorman.gov.tr/SYGM/Belgeler/havza\%20k oruma\%20eylem\%20planlar\%C4\%B1/Sakarya_web.pdf

Yavuz, S., ve Deveci, M. (2012). İstatistiksel normalizasyon tekniklerinin yapay sinir ağın performansına etkisi. Erciyes Üniversitesi İktisadi ve İdari Bilimler Fakültesi Dergisi, 40, 167-187. https://dergipark.org.tr/tr/pub/erciyesiibd/issue/5897/78019

Yaykıran, S. (2016). Sakarya Havzası'nın yüksek çözünürlüklü hidrolojik modelinin yapılandırılması. Yüksek Lisans Tezi. İstanbul Teknik Üniversitesi Fen Bilimleri Enstitüsü, İstanbul. Erişim adresi http://hdl.handle.net/11527/13074

Yılmaz, B. (2015). Akarçay havzasında çözünmüş oksijen değerlerinin yapay sinir ağları ile belirlenmesi. Uzmanlık Tezi. T.C. Orman ve Su İşleri Bakanlığı Su Yönetimi Genel Müdürlüğü, Ankara. $\quad$ Erişim adresi https://www.tarimorman.gov.tr/SYGM/Belgeler/TEZLER/B ekirYilmazTez\%20(2).pdf

Zheng, L., Chen, C. ve Zhang, F. Y. (2004). Development of water quality model in the Satilla River Estuary, Georgia. Ecological Modelling, 178 (3), 457-482. https://doi.org/10.1016/j.ecolmodel.2004.01.016 